\title{
Analytical method validation for assay determination of cannabidiol and tetrahydrocannabinol in hemp oil infused products by RP-HPLC
}

\author{
Eric Moore ( $\nabla$ e.moore@ucc.ie) \\ University College Cork \\ Sandhyarani Analakkattillam \\ University College Cork \\ Victor Langsi \\ University College Cork \\ John Hanrahan \\ Glantreo Ltd
}

\section{Research Article}

Keywords: Cannabidiol, tetrahydrocannabinol, hemp oil, RP-HPLC, assay, method validation

Posted Date: January 31st, 2022

DOI: https://doi.org/10.21203/rs.3.rs-1268404/v1

License: () (1) This work is licensed under a Creative Commons Attribution 4.0 International License. Read Full License 


\section{Abstract}

A simple quantitative reverse phase high performance liquid chromatographic (RP-HPLC) method has been developed and validated for assay determination of cannabidiol and tetrahydrocannabinol in hemp oil infused products. The RP-HPLC method was developed and optimized for the mobile phase composition, flow rate, column selection and detector wavelength. An isocratic elution of samples performed on SOLAS $100 \AA$ C $18150 \mathrm{~mm} \times 4.6 \mathrm{~mm}, 5 \mu \mathrm{m}$ column with a mobile phase containing 75/25 acetonitrile/water v/v, delivered at a flow rate $1.5 \mathrm{~mL} /$ minutes to an Ultraviolet - Visible (UV/Vis) detector using $214 \mathrm{~nm}$. The RP-HPLC method was validated to meet regulatory requirements and covers specificity, accuracy, range, linearity, precision, system suitability and robustness. The validated assay test method was applied successfully to quantify cannabidiol and tetrahydrocannabinol in commercial hemp oil infused products such as tablets, soft gel capsules, plant extract oils, oral drops, tincture, and beverage enhancers. All test results were found acceptable as per ICH guidelines, and this confirmed that the method is fit for its intended use in regular quality control and assay of cannabidiol and tetrahydrocannabinol in hemp oil infused products.

\section{Introduction:}

Testing of hemp oil infused products for its purity and quality, helps the consumers to make decisions upon purchasing hemp products, depends on the strength and composition. Moreover, for medicinal cannabis, accurate testing is important as the patients demand specific therapeutic effects. Cannabis is a plant belongs to the family Cannabaceae and contains various natural constituents. A total of 565 compounds have been isolated and identified from the $C$. sativa species where 120 belongs to the category of cannabinoids ${ }^{1,2}$. Cannabinoids belongs to a group of terpenophenolic compounds with 21 carbon atoms and are further divided into 11 subgroups according to their chemical structure. This constitutes 7 compounds of Cannabidiol (CBD), 16 compounds of Cannabigerol (CBG), 23 compounds of $\Delta$-tetrahydrocannabinol ( $\Delta$ 9-THC), 5 compound of $\Delta 8$-tetrahydrocannabinol $(\Delta 8$ - $\mathrm{THC}), 11 \mathrm{compounds}$ of Cannabinol (CBN), 9 compounds of Cannabichromene (CBC), 5 compounds of Cannabielsoin (CBE), 2 compounds of Cannabinodiol (CBND), 3 compounds of Cannabicyclol (CBL), 9 compounds of Cannabitriol (CBT) types and remaining 30 compounds belongs to miscellaneous type ${ }^{3}$. CBD, THC, $\mathrm{CBG}, \mathrm{CBN}$, and $\mathrm{CBC}$ are neutral cannabinoids and are synthesised by decarboxylation reaction of their respective naturally occurring acid forms (CBDA, THCA, CBGA, CBNA, and CBCA). Out of 120 cannabinoids, CBD and THC are the two major biomarkers in commercial hemp oil samples ${ }^{4}$. CBD (Fig. 1a), the active pharmaceutical ingredient (API) found in the medicinal hemp oil products, shows several curative properties such as anti-psychotic, anti-anxiety, antiemetic, appetiteenhancing, analgesic, and muscle relaxant effects ${ }^{5}$. On the other hand, THC (Fig. 1b) is the principal psychoactive constituent of cannabis, contributes the use of cannabis as a recreational drug ${ }^{5}$. According to the US Farm bill 2018 , hemp is defined as 'the plant cannabis sativa $L$. and any part of that plant, including the seeds thereof and all derivatives, extracts, cannabinoids, isomers, acids, salts, and salts of isomers, whether growing or not, with a delta-9

tetrahydrocannabinol concentration of not more than 0.3 percent on a dry weight basis' ${ }^{6}$. That makes the need for a quantitative method for the simultaneous determination of both CBD and THC in hemp products because the composition of both CBD and THC levels have a strong influence on the effects on the final product.

Literature survey revealed that there have been several analytical methods to quantify cannabinoids and most methods utilise gas chromatography (GC) coupled with mass spectrometry (MS) detectors as an effective tool to analyse cannabis products $7,8,9,10,11,12,13,14$. The GC method limits the quantification of acidic analogues as a result of decarboxylation due to hot inlet and oven conditions. Moreover, the decarboxylation process was found to be incomplete which in turn makes in difficulty to quantitate the analysis. In GC, the determination of acidic cannabinoids requires extensive derivatization steps ${ }^{15}$. For the quantification of both acidic and neutral cannabinoids, methods based on high performance liquid chromatography (HPLC) ${ }^{16}$, thin layer chromatography $(\mathrm{TLC})^{17}$, HPLC coupled with mass spectrometry (HPLC/MS) ${ }^{18}$, ultra-high performance supercritical fluid chromatography (UHPSFC) ${ }^{19}$, liquid chromatography coupled with MS (LC-MS) $20,21,23$, and centrifugal partition chromatographic techniques ${ }^{24}$ have been reported. Methods showing quantitative determination of CBD in pure isolate was also published earlier ${ }^{25}$. Out of all the methods, the HPLC method found to be the simplest as it allows the determination of both acidic and neutral forms and also, the system not requires expensive MS detectors. A lot number of methods were published that uses HPLC system ${ }^{26,27,28,29,}$ 30,31 , where most of these methods use buffer mobile phases and gradient elution techniques ${ }^{32,33}$. Moreover, these methods demonstrate the separation of cannabinoid mixture where it includes several cannabinoids apart from CBD and $\mathrm{THC}^{28,34,35,36}$. The hemp industry demands the development of easy, robust, accurate and efficient novel analytical methodologies for the quantification of the main constituents such as CBD and THC, as the regulatory requirements changes so rapidly. Hemp oil is used to formulate several consumer goods such as food supplements in the form of liquid formulations, beverage enhancers, chocolates, capsules, topicals, baked goods, and as non-prescription medicines in the form of tablets, tinctures, capsules, oral drops, and sublingual drops.

Here, we demonstrate the feasibility of reverse phase HPLC (RP-HPLC) method for reliable and fast quantitative determination of CBD and THC in hemp oil products. The proposed method uses isocratic elution that makes the method feasible to perform in any standard HPLC system. Also, the method performs well in ambient temperature conditions and uses a mobile phase of organic modifier only. Specificity, linearity, accuracy, range, precision, and robustness of the analytical method were determined according to assay method validation requirements specified in the International council for harmonization (ICH) quality guideline Q2(R1), "Validation of Analytical Procedures: Test and Methodology" for quantitation of CBD and THC by liquid chromatography ${ }^{37}$.

\section{Materials And Methods:}

\section{Equipment:}

RP-HPLC analysis was performed in Jasco Extrema (JASCO, Inc., 28600 Mary's court, Easton, Maryland 21601, USA) connected with in built autosampler (AS4150), quaternary pump (PU-4180) with an on-line degasser, column oven (CO-4061), UV/Vis detector (UV-4075) and an interface box LC-Netll/ADC. Chromatographic data was collected and analysed using ChromNAV Ver.2 software. Second HPLC system (Agilent 1100 series) equipped with variable 
wavelength detector (G1314A VWD), autosampler (G1313A) and isocratic pump system (G1310A) uses Chemstation (Agilent technologies) software was used for performing intermediate precision (repeatability) testing. Chromatographic separations were achieved by using SOLAS $100 \AA$ C18 $150 \mathrm{~mm} \times 4.6 \mathrm{~mm}$ $5 \mu \mathrm{m}$ column (Glantreo limited, Ireland), and also, different HPLC columns such as SOLAS ${ }^{\mathrm{TM}}$ ODS C18 $150 \mathrm{~mm} \times 4.6 \mathrm{~mm} 5 \mu \mathrm{m}$, SOLAS ${ }^{\mathrm{Tm}}$ ODS C18 $150 \mathrm{~mm} \times$ $4.6 \mathrm{~mm} 3 \mu \mathrm{m}$, SOLAS ${ }^{\mathrm{TM}}$ BDS C18 $150 \mathrm{~mm} \times 4.6 \mathrm{~mm} 5 \mu \mathrm{m}$, SOLAS ${ }^{\mathrm{TM}} \mathrm{C} 18150 \mathrm{~mm} \times 4.6 \mathrm{~mm} 3 \mu \mathrm{m}$ and Eiroshell ${ }^{\mathrm{TM}} \mathrm{C} 18150 \mathrm{~mm} \times 4.6 \mathrm{~mm} 2.6 \mu \mathrm{m}$ provided from Glantreo limited were used for method development purpose. All chemicals and test samples were accurately weighed using an analytical balance (Adventurer Pro AS214, Ohaus corporation, Pine Brook, NJ USA).

\section{Chemicals and reagents:}

All reagents and chemicals of HPLC or analytical grade were used, that includes acetonitrile from Alfa Aesar (Thermo Fisher scientific, Lancashire, United Kingdom) and distilled water from in-house facility. Cannabidiol (CBD) and $\Delta^{9}$ - Tetrahydrocannabinol ( $\Delta^{9}$-THC or THC) reference standards were commercially purchased from Cerilliant (Cerilliant Corporation, Round Rock, Texas, United States). Phytocannabinoid mixture 10 was purchased from Cayman chemical (Cayman chemical company, 1180 East Ellsworth Road, Ann Arbor, Michigan 48108 USA). Prism Science LLC, 30403 Kings Valley Dr., Conifer, CO 80433 kindly provided CBD tablets (Santeer LUV 5mg CBD Tablets-Medium) and the tablet placebo for testing. Millex-LCR PTFE 0.45um membrane filters were purchased from Merck Millipore Ltd., Tullagreen, Carrigtwohill, Co. Cork, Ireland.

\section{Chromatographic conditions used:}

A mobile phase of acetonitrile and water $75 / 25 \mathrm{v} / \mathrm{v}$ with isocratic flow rate of $1.5 \mathrm{~mL} /$ minutes were used. Column temperature was maintained at $25^{\circ} \mathrm{C}$ and detection was made at $214 \mathrm{~nm}$. $10 \mu \mathrm{L}$ of standard and sample solutions were injected in the HPLC system, where a run time of 10 minutes for CBD standard and 20 minutes for system suitability and assay samples were used. For method development, $20 \mu \mathrm{L}$ of phytocannabinoid mixture 10 working standard solution was injected in the HPLC system.

\section{Preparation of stock standard solutions:}

Stock standard solutions of $100 \mu \mathrm{g} / \mathrm{mL} \mathrm{CBD}$ and $100 \mu \mathrm{g} / \mathrm{mL}$ THC was prepared by dissolving $1.0 \mathrm{~mL}$ of CBD and THC reference standards to $10 \mathrm{~mL}$ with acetonitrile in volumetric flasks separately. Diluted $1.0 \mathrm{~mL}$ of THC stock standard solution to $10 \mathrm{~mL}$ with acetonitrile and used as final standard stock containing $10 \mu \mathrm{g} / \mathrm{mL}$ of THC.

\section{Method Development:}

To optimise the chromatographic method parameters, working standard solution of $10 \mu \mathrm{g} / \mathrm{mL}$ CBD, prepared by diluting $1.0 \mathrm{~mL}$ of CBD stock standard to 10 $\mathrm{mL}$ with acetonitrile, and $25 \mu \mathrm{g} / \mathrm{mL}$ phytocannabinoid mixture 10 working standard solution, prepared by diluting $1.0 \mathrm{~mL}$ of $250 \mu \mathrm{g} / \mathrm{mL}$ standard solution to $10 \mathrm{~mL}$ with acetonitrile were used. Mobile phase varying from 60/40 v/v to $80 / 20 \mathrm{v} / \mathrm{v}$ acetonitrile/water were considered and flow rate of $1.5 \mathrm{~mL} / \mathrm{minutes}$ and $2.0 \mathrm{~mL} /$ minutes were studied. After optimising the mobile phase and flow rate parameters, testing was conducted in different wavelengths such as $214 \mathrm{~nm}$, $228 \mathrm{~nm}, 230 \mathrm{~nm}, 240 \mathrm{~nm}, 280 \mathrm{~nm}$, and $305 \mathrm{~nm}$. Chromatographic columns of $150 \times 4.6 \mathrm{~mm}$ with different particle size and column chemistry were tested. The columns considered were SOLAS ${ }^{\mathrm{TM}} \mathrm{C} 185 \mu \mathrm{m}$, SOLAS ${ }^{\mathrm{TM}}$ ODS $5 \mu \mathrm{m}$ and $3 \mu \mathrm{m}$, SOLAS ${ }^{\mathrm{TM}}$ BDS $5 \mu \mathrm{m}$ and $3 \mu \mathrm{m}$, and Eiroshell ${ }^{\mathrm{TM}} \mathrm{C} 182.6 \mu \mathrm{m}$. The one with better efficiency and separation was chosen for final testing.

\section{System suitability :}

For assay method, mixed $1.0 \mathrm{~mL}$ each of CBD and THC stock standard solutions to $10 \mathrm{~mL}$ with acetonitrile in a volumetric flask (standard mixture of concentration $10 \mu \mathrm{g} / \mathrm{mL} \mathrm{CBD}$ and $1 \mu \mathrm{g} / \mathrm{mL}$ THC each). This solution was used for system suitability testing where six injections were made in HPLC and determined the plate count, tailing factor, resolution, and reproducibility (percent RSD of retention time, peak area, and height for six injections).

\section{Linearity:}

Assay linearity was demonstrated by preparing five standard solutions within the range of $50-150 \%$ of the nominal sample concentration ( $0.1 \mathrm{mg} / \mathrm{mL})$. Each solution was prepared by serial dilution from a single stock ( $5 \mu \mathrm{g} / \mathrm{mL}$ to $15 \mu \mathrm{g} / \mathrm{mL}$ for CBD and $0.5 \mu \mathrm{g} / \mathrm{mL}$ to $1.5 \mu \mathrm{g} / \mathrm{mL}$ for THC) and was injected in triplicate. Linear regression analysis was performed, excluding the origin as a point.

\section{Specificity:}

For specificity, prepared un-spiked placebo solutions by weighing placebo equivalent to one placebo blend tablet weight (weighed 20 tablets and calculated the average weight) and transferred into a $50 \mathrm{~mL}$ volumetric flask, added $35 \mathrm{~mL}$ of acetonitrile, and sonicated for 20 minutes. Diluted to volume with acetonitrile and mixed well (un-spiked placebo stock). Diluted $1.0 \mathrm{~mL}$ of this solution to $10 \mathrm{~mL}$ with acetonitrile, mixed well, filtered into auto sampler vial after discarding $2.0 \mathrm{~mL}$ of filtrate using $0.45 \mu \mathrm{m}$ Millex PTFE filter unit. The placebo preparation was injected in duplicate. Prepared two separate spiked solutions containing the active at $100 \%$ by preparing un-spiked placebo stock separately and diluted $1.0 \mathrm{~mL}$ to $10 \mathrm{~mL}$ with acetonitrile, added $1.0 \mathrm{~mL}$ of $\mathrm{CBD}$ stock standard and $1.0 \mathrm{~mL}$ of THC final stock standard solutions, mixed well, filtered into auto sampler vial after discarding $2.0 \mathrm{~mL}$ of filtrate using $0.45 \mu \mathrm{m}$ Millex PTFE filter unit. (Spiked concentration: CBD - $10 \mu \mathrm{g} / \mathrm{mL}$ and THC $-1 \mu \mathrm{g} / \mathrm{mL}$ each). Injected the spiked samples twice to confirm specificity.

\section{Range:}

Range for the assay method was demonstrated by analysing placebo solutions spiked in a range between $50 \%$ and $150 \%$ of the nominal method sample concentration of CBD $(10 \mu \mathrm{g} / \mathrm{mL})$ and THC $(1 \mu \mathrm{g} / \mathrm{mL})$. Three weights were prepared at each of five concentration levels and each solution was analysed in triplicate. Linear regression analysis was performed, excluding the origin as a point.

\section{Accuracy:}


Accuracy and recovery of the method for assay was validated by analysing data obtained from spiked placebo solutions during the range portion of the validation. The percent recovery of each individual sample weight and the average at each concentration level was determined.

\section{Precision:}

For precision, assay sample solutions are prepared as follows:

Accurately weighed a minimum of five tablets, calculated the average weight of each tablet and ground into fine powder. Weighed sample equivalent to $5 \mathrm{mg}$ of CBD and transferred into a $50 \mathrm{~mL}$ volumetric flask. Added about $35 \mathrm{~mL}$ of acetonitrile and sonicated for 15 minutes with intermitted shaking. Diluted to volume with acetonitrile and mixed well. Diluted $1.0 \mathrm{~mL}$ of this solution to $10 \mathrm{~mL}$ with acetonitrile and mixed well. Filtered a portion through Millex PTFE 0.45 $\mu \mathrm{m}$ sample filtration kit into HPLC vials after discarding $2 \mathrm{~mL}$ of sample solution. Sample contains $10 \mu \mathrm{g} / \mathrm{mL} \mathrm{CBD}$ in it. $10 \mu \mathrm{L}$ of sample solutions were injected into HPLC system.

For method precision (repeatability), six assay samples prepared and percent label claim for CBD and THC were determined for each sample. Intermediate precision of the method was demonstrated by repeating the repeatability experiment with a second analyst. This analyst used different solution preparations, reagents, operating conditions, column, and HPLC systems and tested on different days from the first analyst.

\section{Robustness:}

Method robustness was established by variation of chromatographic parameters to indicate the reliability of the proposed analytical method during normal usage. The chromatographic parameters considered were variation in mobile phase composition, column oven temperature and mobile phase flow rate. In mobile phase composition increased the major component by $5 \%$ and $10 \%$, column oven temperature was increased and reduced by $5^{\circ} \mathrm{C}$ and flow rate increased and decreased by $10 \%$ and $25 \%$ from the proposed method condition. System suitability standard solution was injected in duplicate with each parameter change.

\section{Results And Discussion:}

The assay method was developed and validated according to ICH guidelines with respect to system suitability, linearity, specificity, accuracy, range, precision (repeatability and intermediate precision) and robustness.

\section{Method Development:}

The focus of our research was to develop a new analytical method for the simultaneous determination of CBD and THC in hemp oil infused products. Moreover, the method proposed here can be utilized in commercial drug testing laboratories, pharmaceutical industries, and research laboratories as a standard quality control procedure. The simplest HPLC methods make use of isocratic elution techniques where the mobile phase consists of only organic modifiers were reported ${ }^{38,39}$. Optimization of chromatographic conditions play a major role in the accurate detection and quantification of analytes in HPLC techniques. Mobile phases containing different percentage of acetonitrile $(60,70,75$ and $80 \%, v / v)$ were studied and noted the elution time for CBD and resolution between $\mathrm{CBD}$ and $\mathrm{CBG}$. During the testing for different mobile phase compositions, a flow rate of $2.0 \mathrm{~mL} / \mathrm{minutes}$ and detection wavelength of 214 $\mathrm{nm}$ were employed. Detection wavelength of $305 \mathrm{~nm}$ was used to identify the CBN in phytocannabinoid mixture as CBN generates intense peak at $305 \mathrm{~nm}$. The test results lead to propose a mobile phase concentration of $75 / 25 \mathrm{v} / \mathrm{v}$ acetonitrile/water. Flow rate of $1.5 \mathrm{~mL} / \mathrm{minutes}$ and $2.0 \mathrm{~mL} / \mathrm{minutes}$ were compared and finalised the flow rate as $1.5 \mathrm{~mL} /$ minutes where CBD eluted with better efficiency. Different wavelengths $(214 \mathrm{~nm}, 228 \mathrm{~nm}, 230 \mathrm{~nm}, 240 \mathrm{~nm}$, $280 \mathrm{~nm}$, and $305 \mathrm{~nm}$ ) were checked and the peak intensity for CBD was noted. Different chromatographic columns with $150 \mathrm{~mm} \times 4.6 \mathrm{~mm}$ column dimensions were tested for their ability to resolve CBD and THC from other cannabinoids. All the columns tested were manufactured by Glantreo limited using

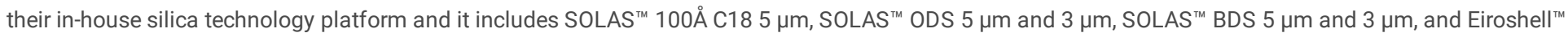
C18 $2.6 \mu \mathrm{m}$. All the test results were tabulated in Table 1(a, b, and c). 
Table 1

(a): Method development - Mobile phase and Flow rate optimization at $214 \mathrm{~nm}$

\begin{tabular}{|c|c|c|c|c|c|c|}
\hline $\begin{array}{l}\text { Mobile phase } \\
\text { composition } \\
\text { (Acetonitrile/water } \\
\text { v/v) }\end{array}$ & Flow rate (mL/minutes) & $\begin{array}{l}\text { Retention time (CBD } \\
\text { standard) minutes }\end{array}$ & $\begin{array}{l}\text { Number of } \\
\text { theoretical plates } \\
\text { (N) CBD Standard }\end{array}$ & $\begin{array}{l}\text { Symmetry (CBD } \\
\text { Standard) }\end{array}$ & $\begin{array}{l}\text { Resolution CBG/CBD } \\
\text { (Cannabinoid mixture } \\
\text { 10) }\end{array}$ & $\begin{array}{l}\text { Retention } \\
\text { (cannabin } \\
\text { mixture 10 } \\
\text { minutes* }\end{array}$ \\
\hline $60 / 40$ & 2.0 & 18.576 & 6894 & 1.09 & CBG peak not detected & 55.625 \\
\hline $70 / 30$ & 2.0 & 7.735 & 6704 & 1.14 & 0.76 & 21.123 \\
\hline $70 / 30$ & 1.5 & 10.292 & 7995 & 1.11 & 0.93 & 28.018 \\
\hline \multirow[t]{2}{*}{$75 / 25$} & 2.0 & 5.209 & 6317 & 1.21 & 1.12 & 13.372 \\
\hline & 1.5 & 6.918 & 7644 & 1.19 & 1.23 & 17.546 \\
\hline \multirow[t]{2}{*}{$80 / 20$} & 2.0 & 3.654 & 5648 & 1.19 & 1.25 & 8.724 \\
\hline & 1.5 & 4.848 & 6960 & 1.23 & 1.39 & 11.566 \\
\hline
\end{tabular}

${ }^{*} \mathrm{CBC}$ was eluted as the last peak in phytocannabinoid mixture 10 and was considered to choose the total run time for the samples.

Table 1(b): Method development - Optimization for detector wavelength where Table 1(c): Method development - Chromatographic column selection mobile phase was fixed as $75 / 25 \mathrm{v} / \mathrm{v}$ acetonitrile/water and flow rate 1.5 $\mathrm{mL} /$ minutes.

\begin{tabular}{|c|c|c|c|c|c|c|c|c|}
\hline $\begin{array}{l}\text { UV } \\
\text { wavelength } \\
\text { (nm) }\end{array}$ & $\begin{array}{l}\text { Peak Area } \\
\text { (CBD } \\
\text { standard) }\end{array}$ & $\begin{array}{l}\text { Peak height (CBD } \\
\text { standard) }\end{array}$ & N (CBD standard) & $\begin{array}{l}\text { Columns used } \\
(150 \mathrm{~mm} \times 4.6 \\
\mathrm{mm} 100 \AA)\end{array}$ & $\begin{array}{l}\text { Retention time } \\
\text { (CBD Standard) } \\
\text { minutes }\end{array}$ & $\begin{array}{l}\mathrm{N} \text { (CBD } \\
\text { Standard) }\end{array}$ & $\begin{array}{l}\text { Symmetry } \\
\text { (CBD } \\
\text { Standard) }\end{array}$ & $\begin{array}{l}\text { Res } \\
\text { (CB } \\
\text { can } \\
\text { mix }\end{array}$ \\
\hline 214 & 374090 & 30108 & 7644 & $\begin{array}{l}\text { SOLAS }{ }^{\mathrm{TM}} \mathrm{C} 185 \\
\mu \mathrm{m}\end{array}$ & 6.918 & 7644 & 1.191 & $1.2:$ \\
\hline 228 & 136453 & 10892 & 7441 & $\begin{array}{l}\text { SOLAS }^{\mathrm{TM}} \text { ODS C18 } \\
5 \mu \mathrm{m}\end{array}$ & 3.129 & 3570 & 1.174 & NR \\
\hline 230 & 122916 & 9842 & 7398 & $\begin{array}{l}\text { SOLAS } \\
3 \mu \mathrm{m} \text { ODS C18 }\end{array}$ & 2.625 & 6819 & 1.009 & NR \\
\hline 240 & 46056 & 3696 & 7385 & $\begin{array}{l}\text { SOLAS }{ }^{\mathrm{TM}} \text { BDS C18 } \\
5 \mu \mathrm{m}\end{array}$ & 2.841 & 6438 & 1.047 & NR \\
\hline 280 & 10291 & 822 & 7324 & $\begin{array}{l}\text { SOLAS } \\
3 \mu \mathrm{m} \text { BDS C18 }\end{array}$ & 2.863 & 7481 & 1.081 & NR \\
\hline **305 & ND & ND & ND & $\begin{array}{l}\text { EIROSHELL }{ }^{\mathrm{TM}} \mathrm{C} 18 \\
2.6 \mu \mathrm{m}\end{array}$ & 3.123 & 4278 & 1.169 & $0.9 !$ \\
\hline
\end{tabular}

From Table 1(a), it was clear that a mobile phase of $75 / 25 \mathrm{v} / \mathrm{v}$ acetonitrile/water with a flow rate $1.5 \mathrm{~mL} / \mathrm{minutes}$ enables the CBD peak to elute with better efficiency and also, with comparatively better separation from CBG. Table 1(b) showed that detector wavelength of both $214 \mathrm{~nm}$ and $228 \mathrm{~nm}$ were suitable as in higher wavelengths the peak intensity for CBD has been reduced. In this proposed method $214 \mathrm{~nm}$ was considered as optimal wavelength as in this wavelength CBD elutes with higher peak intensity and better efficiency. Table 1(c) revealed that SOLAS ${ }^{\mathrm{TM}} \mathrm{C} 18150 \mathrm{~mm} \times 4.6 \mathrm{~mm} 5 \mu \mathrm{m}$ column shown well separation for phytocannabinoid mixture 10 with a superior resolution between CBG and CBD as compared to the SOLAS ${ }^{\mathrm{TM}}$ ODS $5 \mu \mathrm{m}$, BDS $5 \mu \mathrm{m}$ and Eiroshell $^{\mathrm{Tm}} 2.6 \mu \mathrm{m} \mathrm{C18}$ columns. Moreover, SOLAS ${ }^{\mathrm{Tm}} \mathrm{C} 18150 \mathrm{~mm} \times 4.6 \mathrm{~mm} 5 \mu \mathrm{m}$ column demonstrated higher efficiency in terms of number of theoretical plates for CBD and also, with CBD peak symmetry $\leq 1.5$.

\section{System suitability testing:}

System suitability test performed for standard mixture containing $10 \mu \mathrm{g} / \mathrm{mL}$ CBD and $1 \mu \mathrm{g} / \mathrm{mL}$ THC and six replicate injections were made in both HPLC systems. The observed RSD values for retention time, peak area, and peak height, are well within the set limits of acceptance criteria of less than $1 \%$. Theoretical plates (N), USP tailing factor (T), Capacity factor, USP resolution (Rs) between CBD and THC, and relative retention time (RRT) of THC were determined for assay. The results are summarized in Table 2(a) and all results are within the set acceptable limit mentioned in Table 2(a). A typical system suitability chromatogram was shown in Figure 2. 
Table 2

System suitability and Validation results

\begin{tabular}{|c|c|c|c|c|c|c|c|c|c|c|c|}
\hline \multicolumn{4}{|c|}{$\begin{array}{l}\text { Table 2(a): System suitability parameters } \\
\text { for assay method validation }\end{array}$} & \multicolumn{8}{|c|}{ Table 2(b): Validation results of the RP-HPLC assay test method for CBD and THC } \\
\hline \multirow{2}{*}{$\begin{array}{l}\text { System } \\
\text { Suitability } \\
\text { Parameter }\end{array}$} & \multirow{2}{*}{$\begin{array}{l}\text { Acceptance } \\
\text { Criteria }\end{array}$} & \multicolumn{2}{|c|}{ Results } & \multirow[t]{2}{*}{ Compound } & \multirow{2}{*}{$\begin{array}{l}\text { Amount } \\
\text { of } \\
\text { standard } \\
\text { added } \\
(\mu \mathrm{g} / \mathrm{mL})\end{array}$} & \multirow{2}{*}{$\begin{array}{l}\text { Linearity } \\
\left(r^{2}\right)\end{array}$} & \multirow{2}{*}{$\begin{array}{l}\text { Accuracy } \\
\text { (\% } \\
\text { recovery) }\end{array}$} & \multirow{2}{*}{$\begin{array}{l}\text { Range } \\
\text { \% RSD (3 } \\
\text { preparations } \\
\text { / } 9 \\
\text { injections }\end{array}$} & \multicolumn{3}{|c|}{ Precision (\% RSD) } \\
\hline & & CBD & THC & & & & & & $r^{2}$ & Repeatability & $\begin{array}{l}\text { Intermediate } \\
\text { precision }\end{array}$ \\
\hline \multirow{2}{*}{$\begin{array}{l}\text { Injection } \\
\text { precision } \\
\text { for } \\
\text { retention } \\
\text { time (min) }\end{array}$} & $\mathrm{RSD} \leq 1 \%$ & 0.42 & 0.53 & \multirow[t]{6}{*}{ CBD } & 5 & \multirow[t]{6}{*}{0.9999} & 100.14 & 0.14 & \multirow[t]{6}{*}{0.9997} & \multirow[t]{6}{*}{0.23} & \multirow[t]{6}{*}{0.14} \\
\hline & & & & & 7 & & 102.38 & 0.46 & & & \\
\hline $\begin{array}{l}\text { Injection } \\
\text { precision } \\
\text { for peak } \\
\text { area }(\mathrm{n}= \\
6)\end{array}$ & $\mathrm{RSD} \leq 1 \%$ & 0.11 & 0.67 & & 10 & & 105.17 & 0.62 & & & \\
\hline $\begin{array}{l}\text { Injection } \\
\text { precision } \\
\text { for }\end{array}$ & $\mathrm{RSD} \leq 1 \%$ & 0.62 & 0.68 & & 13 & & 104.86 & 0.78 & & & \\
\hline $\begin{array}{l}\text { peak } \\
\text { height }\end{array}$ & & & & & & & & & & & \\
\hline $\begin{array}{l}\text { Resolution } \\
\text { (Rs) }\end{array}$ & Rs $\geq 2.0$ & - & 16.12 & & 15 & & 104.38 & 0.28 & & & \\
\hline $\begin{array}{l}\text { USP tailing } \\
\text { factor }(T)\end{array}$ & $\mathrm{T} \leq 2.0$ & 1.35 & 1.08 & \multirow[t]{5}{*}{$\mathrm{THC}$} & 0.5 & \multirow[t]{5}{*}{0.9999} & 100.24 & 1.22 & \multirow[t]{5}{*}{0.9996} & \multirow[t]{5}{*}{0.43} & \multirow[t]{5}{*}{0.64} \\
\hline $\begin{array}{l}\text { Capacity } \\
\text { factor (k) }\end{array}$ & $k \geq 2.0$ & 10.3 & 21.8 & & 0.7 & & 98.85 & 0.65 & & & \\
\hline $\begin{array}{l}\text { Theoretical } \\
\text { plates }(\mathrm{N})\end{array}$ & $N \geq 3000$ & 7970 & 9504 & & 1.0 & & 98.17 & 0.84 & & & \\
\hline \multirow{2}{*}{$\begin{array}{l}\text { Relative } \\
\text { retention } \\
\text { factor } \\
\text { (RRT) }\end{array}$} & \multirow[t]{2}{*}{2.0} & \multirow[t]{2}{*}{-} & \multirow[t]{2}{*}{2.03} & & 1.3 & & 98.03 & 0.64 & & & \\
\hline & & & & & 1.5 & & 99.64 & 0.57 & & & \\
\hline
\end{tabular}

\section{Linearity:}

The linearity of peak area response for CBD and THC was determined for assay method by analysing standard mixture with serial dilutions from 50 to $150 \%$ of the method concentration ( $10 \mu \mathrm{g} / \mathrm{mL}$ for $\mathrm{CBD}$ and $1 \mu \mathrm{g} / \mathrm{mL}$ for $\mathrm{THC}$ ). Linear regression analysis was performed, excluding the origin as a point. For both CBD and THC, percentage RSD for the peak area for the triplicate injections were found to be less than $1.0 \%$ and exhibits linear responses with $r^{2}>0.999$ (Table 2(b)). A graph of concentration versus peak area response (intensity) is shown in Figure 3. A graph of the residuals versus analyte concentration is shown in Figure 3. No trend was observed from the residual plot. The y intercept did not show significant departure from zero.

\section{Specificity:}

Prepared placebo solutions by weighing an appropriate amount of placebo (the placebo remains $100 \%$ of method concentration), with respect to the concentration specified in the method being validated. The placebo preparation was injected in duplicate. Prepared two separate spiked solutions containing the active at $100 \%$. Injected the spiked samples twice to confirm specificity. Example chromatograms of diluent blank, un-spiked placebo, and spiked placebo preparations are presented in the Figure 4. The method showed good specificity as no interfering peaks from the diluent and placebo were observed.

\section{Range:}

Placebo solutions spiked with sample concentration ranging from 50 to $150 \%$ of method concentration was prepared in triplicate. Three injections were made from each preparation, and linear regression analysis was performed, excluding the origin as a point. Both CBD and THC standards show linear responses with an $r^{2}>0.999$ (Table 2(b)). Also, percentage RSD for average area responses for the triplicate injections and for each concentration level $(n=9$, where $n$ is number of injections made) was found to be less than $2.0 \%$ (Table 2(b)). A graph of concentration versus area response is shown in Figure 5 . A graph of the residuals versus analyte concentration was plotted and no trend was observed from the residual plot. The y intercept did not show significant departure from zero.

\section{Accuracy:}

Percentage recovery at each individual spiked placebo samples and the average at each concentration level was calculated. The results were tabulated in Table 2(b). The percentage recovery of the spiked placebos was found to be $100-105 \%$ for CBD and $98-100 \%$ for THC (acceptance criteria: $90-110 \%$ as per ICH 
guidelines) for the average of each set of three weights. Each individual sample recovery also found within the range of $90 \%-110 \%$. After examination of the recovery data, the method was determined to have no bias and the method is demonstrating a high extraction efficiency for CBD and THC.

\section{Precision:}

Method precision (repeatability) was performed by preparing six sample solutions from the tablets for a concentration of $10 \mu \mathrm{g} / \mathrm{mL} \mathrm{CBD}$ where equivalent of 5 mg CBD was weighed. Each preparation was injected twice, and the assay values calculated. Results including the percentage RSD values of CBD and THC for both repeatability and intermediate precision are presented in Table 2(b). Percentage RSD values for both CBD and THC are below 2.0\%. The chromatograms of a typical standard and sample solutions $(5 \mathrm{mg})$ were shown in Figure 6 . The sample chromatogram was compared with the chromatograms of standard, placebo and blank. As CBG was appeared to be slightly overlapping with CBD in the hemp oil sample chromatogram, still the separation was distinct to allow a proper integration. Intermediate precision of the method was demonstrated by repeating the repeatability experiment with a second analyst. This analyst used different solution preparations, reagents, operating conditions, column, and HPLC systems and tested on different days from the first analyst. All acceptance criteria were met (The percentage RSD of the assay values should not be greater than $2.0 \%$. The percentage RSD of the combined assay values from both analysts should be not more than $3.0 \%$ as per ICH guidelines).

\section{Robustness:}

Method robustness was proved by variation of the mobile phase composition, temperature, and flow rate, from the parameters specified in proposed method. A system suitability standard $(10 \mu \mathrm{g} / \mathrm{mL}$ CBD and $1.0 \mu \mathrm{g} / \mathrm{mL} \mathrm{THC})$ was prepared and injected in duplicate with each parameter change. This solution was used to perform robustness for assay and each parameter change was tested one factor at a time. The retention time (RT), theoretical plates ( $N$ ), Tailing factor $(\mathrm{T})$, Capacity factor $(\mathrm{k})$, resolution between CBD and THC (Rs), and the relative retention time (RRT) for THC are reported in Table 3 . Examination of the results from Table 3 suggest that the variation in mobile phase concentration is a critical parameter as with a $5 \%$ and $10 \%$ decrease in major component (acetonitrile) in volume in the mobile phase composition results elution of THC not within the method run time. Besides, a $5 \%$ and $10 \%$ increase in major component in mobile phase composition results poor efficiency (reduced theoretical plate values). Variations in column oven temperature shows no variation in any of the system or column efficiency parameters.

Table 3

Robustness test for HPLC parameter variations_ CBD and THC assay method validation

\begin{tabular}{|c|c|c|c|c|c|c|c|c|c|c|}
\hline \multirow[t]{2}{*}{ Parameter change } & \multicolumn{4}{|l|}{ CBD } & \multicolumn{4}{|l|}{ THC } & \multirow[t]{2}{*}{ Resolution (CBD/THC) } & \multirow[t]{2}{*}{ RRT (THC) } \\
\hline & RT (min) & $\mathbf{N}$ & $\mathrm{T}$ & $\mathrm{K}$ & RT (min) & $\mathbf{N}$ & $\mathrm{T}$ & K & & \\
\hline Method Conditions & 7.03 & 6960 & 1.40 & 10.2 & 14.30 & 7974 & 1.22 & 21.8 & 14.90 & 2.03 \\
\hline Flow $-25 \%$ & 9.44 & 7223 & 1.45 & 13.2 & 19.12 & 7756 & 1.28 & 27.8 & 14.78 & 2.02 \\
\hline Flow $-10 \%$ & 7.82 & 6950 & 1.43 & 12.7 & 15.83 & 7707 & 1.19 & 26.8 & 14.64 & 2.02 \\
\hline Flow $+10 \%$ & 6.38 & 6361 & 1.42 & 10.2 & 12.91 & 7243 & 1.26 & 21.6 & 14.14 & 2.02 \\
\hline Flow $+25 \%$ & 5.59 & 6228 & 1.42 & 10.0 & 11.33 & 7316 & 1.28 & 21.2 & 14.14 & 2.03 \\
\hline Column temp: $+5^{\circ} \mathrm{C}$ & 6.92 & 6864 & 1.37 & 10.2 & 13.91 & 7711 & 1.18 & 21.4 & 14.48 & 2.01 \\
\hline $\begin{array}{l}\text { Column temp: } \\
-5^{\circ} \mathrm{C}\end{array}$ & 7.12 & 6796 & 1.51 & 10.4 & 14.57 & 7850 & 1.32 & 22.3 & 14.89 & 2.05 \\
\hline$M P+10 \%$ & 4.45 & 4197 & 1.29 & 5.5 & 8.54 & 4634 & 1.26 & 11.6 & 10.55 & 1.92 \\
\hline$M P+5 \%$ & 5.69 & 4454 & 1.33 & 7.4 & 11.27 & 4777 & 1.20 & 15.5 & 11.27 & 1.98 \\
\hline MP - $5 \%$ & 9.58 & 7514 & 1.36 & 13.9 & 19.91 & 8567 & 1.07 & 29.9 & 15.91 & 2.08 \\
\hline MP - $10 \%$ & 12.42 & 8500 & 1.25 & 19.5 & 25.97 & 9849 & 1.02 & 41.8 & 17.13 & 2.09 \\
\hline
\end{tabular}

Additionally, solution stability was established for 48 hours by testing system suitability standard solutions twice by using a freshly prepared standard, the solutions kept in room temperature for 24 hours, the solutions kept in $0-8^{\circ} \mathrm{C}$ for 24 hours and the standard solution kept in room temperature for 48 hours. The results show exceedingly small variation in peak area absorbance values and proved the standard solution stability of 48 hours in room temperature. Also, old column where $>500$ injections made was tested and found a higher tailing and backpressure as compared to new column.

\section{Application of final method to marketed hemp oil infused products:}

The proposed validated method was applied for the analysis of various hemp oil infused products and presented ${ }^{40}$. The samples tested were consist of tablets, capsules, tincture, oral drops, beverage-enhancers, and plant extract oils. Furthermore, Glantreo limited is employing this assay method for testing commercial hemp oil infused samples as a quality control procedure.

\section{Conclusion:}

The precise quantitation of compounds like cannabinoids where the products contain psychotic molecules such as THC and the presence and amount of THC makes legal restrictions for the product distribution, demands the laboratories for having affordable and easily applicable validated procedures. The assay 
test method validated and presented here allows the quantitative and simultaneous determination of CBD and THC in Hemp oil infused products in 20 minutes run time. The method uses single wavelength of $214 \mathrm{~nm}$, and the testing can be carried out using any traditional standard RP-HPLC and UV-Visible detectors. Moreover, the method utilizes only organic solvents for standard and preparation, and for mobile phase single organic modifier was involved with no $\mathrm{pH}$ adjustment and the testing follows an isocratic elution. Due to simplicity and consistency this method can be employed by any analyst with basic HPLC knowledge. The method was shown to be selective, precise, linear, and accurate within the range of $50-150 \%$ of the nominal concentration for tablet strengths. The method was shown to be robust with the mobile phase concentration changes and flow rate established as critical parameters.

\section{Abbreviations}

RP-HPLC, Reverse phase high performance liquid chromatography; CBD, Cannabidiol; THC, Tetrahydrocannabinol; RSD, Relative standard deviation; QC, Quality control; ICH, International council for harmonisation; USP, United states pharmacopeia.

\section{Declarations}

\section{Acknowledgements:}

This work was supported by Irish Research Council under the Employment-Based postgraduate programme scholarship (Project ID: EBPPG/2019/38). S. Analakkattillam is thankful to Glantreo limited, ERI Building, Lee Road, Cork, Ireland for allowing to conduct the research in their organisation.

\section{Conflicts of interest / Competing interests:}

The authors declare no competing interests.

\section{Availability of Data and material:}

The authors confirm that the data supporting the results of this study are available upon request from the corresponding author Dr. Eric Moore (e.moore@ucc.ie).

\section{Authors contribution:}

All authors contributed to the study conception and design. Author contribution according to CRediT taxonomy described below:

SA: Methodology, Validation, Formal analysis, Investigation, Writing - Original draft, Visualization, Data curation, Funding acquisition.

EM: Supervision, Writing- Review and Editing.

$\mathrm{JH}$ : Conceptualization, Supervision(Employment mentor), Writing - Review and Editing, Project administration.

VL: Methodology, Validation, Resources.

\section{References}

1. ElSohly, M. A., Mehmedic, Z., Foster, S., Gon, C., Chandra, S. \& Church, J. C. Changes in cannabis potency over the last 2 decades (1995-2014): analysis of current data in the United States. Biol. Psychiatry.79, 613-19. https://doi:10.1016/j.biopsych.2016.01.004 (2016).

2. ElSohly, M. A., Radwan, M. M., Gul, W., Chandra, S. \& Galal, A. Phytochemistry of Cannabis sativa L. Phytocannabinoids. 1-36. https://doi:10.1007/978-3319-45541-9_1 (2017).

3. Radwan, M. M., Wanas, A. S., Chandra, S. \& ElSohly, M. A. Natural Cannabinoids of Cannabis and Methods of Analysis. In: Chandra S, Lata H, ElSohly MA, editors. Cannabis sativa L. - Botany and Biotechnology. 161-182 (Springer International Publishing Cham 2017). https://doi:10.1007/978-3-319-545646_7

4. Zivovinovic, S., Alder, R., Allenspach, M. D. \& Steuer, C. Determination of cannabinoids in Cannabis sativa L. samples for recreational, medical, and forensic purposes by reversed-phase liquid chromatography-ultraviolet detection. J. Anal. Sci. Technol.9, 27. https://doi.org/10.1186/s40543-018-0159-8 (2018).

5. Mechoulam, R. Cannabinoids as therapeutics. Springer 2005. https://doi:10.1007/3-7643-7358-X

6. 7.U.S.C. United States Code. 2015 Edition. Title 7 - Agriculture, Chapter 88 - Research, Subchapter VII - Miscellaneous Research Provisions, Sec. 5940 Legitimacy of industrial hemp research. In: U.S.G.P. Office (Ed.), U.S.G.P. Office, United States. 2015. pp. 1688.

7. Villamor, J. L., Bermejo, A. M., Tabernero, M. J. \& Fernández, P. Determination of Cannabinoids in Human Hair by GC/MS. Anal. Lett.37(3), 517528. https://doi:10.1081/AL-120028624 (2004).

8. Santos, N. Ad. et al. Analysis of isomeric cannabinoid standards and cannabis products by UPLC-ESI-TWIM-MS: a comparison with GC-MS and GC× GCQMS. J. Braz. Chem. Soc.30(1), 60-70. https://doi:10.21577/0103-5053.20180152 (2019). 
9. Lachenmeier, D. W., Kroener, L., Musshoff, F. \& Madea, B. Determination of cannabinoids in hemp food products by use of headspace solid-phase microextraction and gas chromatography-mass spectrometry. Anal. Bioanal. Chem. 378(1), 183-189. https://doi:10.1007/s00216-003-2268-4 (2004).

10. Rodrigues, A., Yegles, M., Van Elsué, N. \& Schneider, S. Determination of cannabinoids in hair of CBD rich extracts consumers using gas chromatography with tandem mass spectrometry (GC/MS-MS). Forensic Sci. Int.292, 163-166. https://doi:10.1016/j.forsciint.2018.09.015 (2018).

11. Cardenia, V., Gallina Toschi, T., Scappini, S., Rubino, R. C. \& Rodriguez-Estrada, M. T. Development and validation of a Fast gas chromatography/mass spectrometry method for the determination of cannabinoids in Cannabis sativa L. J. Food Drug Anal.26(4), 12831292. https://doi:10.1016/j.jfda.2018.06.001 (2018).

12. Leghissa, A., Hildenbrand, Z. L., Foss, F. W. \& Schug, K. A. Determination of cannabinoids from a surrogate hops matrix using multiple reaction monitoring gas chromatography with triple quadrupole mass spectrometry. J. Sep. Sci.41(2), 459-468. https://doi:10.1002/jssc.201700946 (2018).

13. Hillig, K. W. \& Mahlberg, P. G. A chemotaxonomic analysis of cannabinoid variation in Cannabis (Cannabaceae). Am. J. Bot.91(6), 966975. https://doi:10.3732/ajb.91.6.966 (2004).

14. Karschner, E. L., Barnes, A. J., Lowe, R. H., Scheidweiler, K. B. \& Huestis, M. A. Validation of a two-dimensional gas chromatography mass spectrometry method for the simultaneous quantification of cannabidiol, $\triangle 9$-tetrahydrocannabinol (THC), 11-hydroxy-THC, and 11-nor-9-carboxy-THC in plasma. Anal. Bioanal. Chem.397(2), 603-611. https://doi.org/10.1007/s00216-010-3599-6 (2010).

15. Dussy, F.E., Hamberg, C., Luginbühl, M., Schwerzmann, T. \& Briellmann, T. A. Isolation of $\triangle 9-T H C A-A$ from hemp and analytical aspects concerning the determination of $\triangle 9$-THC in cannabis products. Forensic Sci. Int.149(1), 3-10. https://doi:10.1016/j.forsciint.2004.05.015 (2005).

16. Deidda, R. et al. Analytical quality by design: development and control strategy for a LC method to evaluate the cannabinoids content in cannabis olive oil extracts. J. Pharm. Biomed. Anal.166, 326-335. https://doi.org/10.1016/j.jpba.2019.01.032 (2019).

17. Sherma, J. \& Rabel, F. Thin layer chromatography in the analysis of cannabis and its components and synthetic cannabinoids. J. Liq. Chromatogr. Relat. Technol.42(19-20), 613-628. https://doi.org/10.1080/10826076.2019.1663529 (2019).

18. Aizpurua-Olaizola, O., Omar, J., Navarro, P., Olivares, M., Etxebarria, N. \& Usobiaga, A. Identification and quantification of cannabinoids in Cannabis sativa L. plants by high performance liquid chromatography-mass spectrometry. Anal. Bioanal. Chem.406(29), 7549-7560. https://doi:10.1007/s00216-0148177-x (2014).

19. Isaac, G. et al. Ultra-High Performance Supercritical Fluid Chromatography Applications for Natural Products Analysis. Planta Med. Int. Open.4(S 01), S1S202. https://doi:10.1055/s-0037-1608335 (2017).

20. Lebel, P., Waldron, K. C. \& Furtos, A. Rapid determination of 24 synthetic and natural cannabinoids for LC-MS-MS screening in natural products and drug inspection applications. Current Trends in Mass Spectrometry - Supplement to LCGC North America. (2015) 13(1), 8-14.

21. Quintela, O. \& Crouch, D. J. The determination of cannabinoids using liquid chromatography with mass spectrometric detection. In: Langman, L. \& Snozek, C. editors. LC-MS in Drug Analysis. Methods Mol. Biol. (Methods and Protocols) (Humana Press, Totowa, NJ. 2012) 902, 7590. https://doi.org/10.1007/978-1-61779-934-1_7

22. Schwope, D. M., Scheidweiler, K. B. \& Huestis, M. A. Direct quantification of cannabinoids and cannabinoid glucuronides in whole blood by liquid chromatography-tandem mass spectrometry. Anal. Bioanal. Chem.401(4), 1273-1283. https://doi.org/10.1007/s00216-011-5197-7 (2011).

23. McRae, G. \& Melanson, J. E. Quantitative determination and validation of 17 cannabinoids in cannabis and hemp using liquid chromatography-tandem mass spectrometry. Anal. Bioanal. Chem.412(27), 7381-7393. https://doi.org/10.1007/s00216-020-02862-8 (2020)

24. Hazekamp, A. A general introduction to cannabis as medicine. In: Cannabis: extracting the medicine. PhD diss., Institute of Biology Leiden (IBL), Faculty of Science, Leiden University. 2007.

25. Layton, C. E. \& Aubin, A. J. Method validation for assay determination of cannabidiol isolates, J. Liq. Chromatogr. Relat. Technol.41(3), 114121. https://doi:10.1080/10826076.2018.1424637 (2018).

26. De Backer, B. et al. Innovative development and validation of an HPLC/DAD method for the qualitative and quantitative determination of major cannabinoids in cannabis plant material. J. Chromatogr. B.877(32), 4115-4124. https://doi.org/10.1016/j.jchromb.2009.11.004 (2009).

27. Ambach, L., Penitschka, F., Broillet, A., König, S., Weinmann, W. \& Bernhard, W. Simultaneous quantification of delta-9-THC, THC-acid A, CBN and CBD in seized drugs using HPLC-DAD. Forensic Sci. Int.243, 107-111. https://doi:10.1016/j.forsciint.2014.06.008 (2014).

28. Patel, B., Wene, D. \& Fan, Z. T. Qualitative and quantitative measurement of cannabinoids in cannabis using modified HPLC/DAD method. J. Pharm. Biomed. Anal.146, 15-23. https://doi.org/10.1016/j.jpba.2017.07.021 (2017).

29. Fekete, S. et al. Implementation of a generic liquid chromatographic method development workflow: Application to the analysis of phytocannabinoids and Cannabis sativa extracts. J. Pharm. Biomed. Anal.155, 116-124. https://doi.org/10.1016/j.jpba.2018.03.059 (2018).

30. Citti, C., Pacchetti, B., Vandelli, M. A., Forni, F. \& Cannazza, G. Analysis of cannabinoids in commercial hemp seed oil and decarboxylation kinetics studies of cannabidiolic acid (CBDA). J. Pharm. Biomed. Anal.149, 532-540. https://doi.org/10.1016/j.jpba.2017.11.044 (2018).

31. Mudge, E. M., Murch, S. J. \& Brown, P. N. Leaner and greener analysis of cannabinoids. Anal. Bioanal. Chem.409(12), 31533163. https://doi.org/10.1007/s00216-017-0256-3 (2017)

32. Layton, C. \& Reuter, W. M. Analysis of Cannabinoids in Hemp Seed Oils by HPLC using PDA detection. Application Note. PerkinElmer, Shelton, CT, Unites States. (2015). https://cdn.technologynetworks.com/tn/Resources/pdf/analysis-of-cannabinoids-in-hemp-seed-oils-by-hplc-using-pda-detection.pdf. Accessed 13 May 2019.

33. De Vita, D. et al. Comparison of different methods for the extraction of cannabinoids from cannabis. Nat. Prod. Res.34(20), 29522958. https://doi.org/10.1080/14786419.2019.1601194 (2020). 
34. Aubin, A. J., Layton, C. \& Helmueller, S. Separation of 16 Cannabinoids in Cannabis Flower and Extracts Using a Reversed Phase Isocratic HPLC Method, Waters Application Note 720006426EN (2018).

35. Pellati, F., Brighenti, V., Sperlea, J., Marchetti, L., Bertelli, D. \& Benvenuti, S. New Methods for the Comprehensive Analysis of Bioactive Compounds in Cannabis sativa L. (hemp). Molecules.23(10), 2639. https://doi.org/10.3390/molecules23102639 (2018).

36. Lehmann, T. \& Brenneisen, R. High Performance Liquid Chromatographic Profiling of Cannabis Products, J. Liq. Chromatogr.18, 689700. https://doi.org/10.1080/10826079508009265 (1995).

37. Guideline I.H.T. Validation of Analytical Procedures: Text and methodology Q2 (R1) version 4; Proceedings of the International Conference for Harmonization; Geneva, Switzerland (2005).

38. Saingam, W. \& Sakunpak, A. Development and validation of reverse phase high performance liquid chromatography method for the determination of delta-9-tetrahydrocannabinol and cannabidiol in oromucosal spray from cannabis extract. Rev. Bras. Farmacogn.28(6), 669672. https://doi.org/10.1016/j.bjp.2018.08.001 (2018).

39. Zgair, A. et al. Development of a simple and sensitive HPLC-UV method for the simultaneous determination of cannabidiol and $\Delta(9)$-tetrahydrocannabinol in rat plasma. J. Pharm. Biomed. Anal.114, 145-151. https://doi.org/10.1016/j.jpba.2015.05.019 (2015).

40. Analakkattillam, S., Langsi, V. K., Hanrahan, J. P. \& Moore, E. Comparative study of Dissolution for Cannabidiol in EU and US Hemp oil products by HPLC, J. Pharm. Sci.110(8), 3091-3098. https://doi.org/10.1016/j.xphs.2021.03.028 (2021).

\section{Figures}
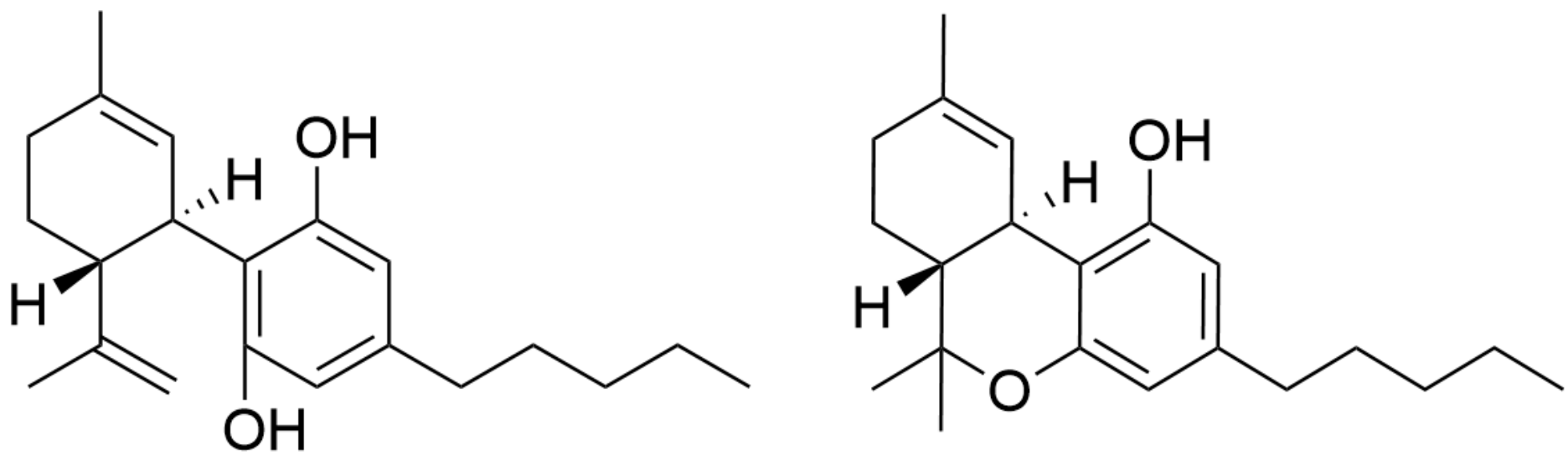

Figure 1

(a) Cannabidiol and 1 (b) Tetrahydrocannabinol - Structural representation of $\mathrm{CBD}$ and THC. Formula: $\mathrm{C}_{21} \mathrm{H}_{30} \mathrm{O}_{2}$; Molecular weight: $314.464 \mathrm{~g} / \mathrm{mol}$

Figure 2

System suitability chromatogram of CBD and THC standard mixture $(10 \mu \mathrm{g} / \mathrm{mL} \mathrm{CBD}$ and $1 \mu \mathrm{g} / \mathrm{mL} \mathrm{THC})$ for assay

\section{Figure 3}

Linearity and residual plot diagrams for CBD and THC assay method validation (a) Residual plot for CBD (b) Residual plot for THC (c) Assay linearity plot for THC and (d) Assay linearity plot for CBD

\section{Figure 4}

Specificity chromatograms of (a) diluent blank (b) un-spiked placebo and (c) spiked placebo samples of CBD and THC assay

\section{Figure 5}

Concentration vs. area response graph of (a) CBD and (b) THC for accuracy and range testing for assay 
Figure 6

(a) Standard and (b) sample chromatograms from precision testing for CBD and THC assay method validation 